\title{
Adverse events of interest vary by influenza vaccine type and brand: Sentinel network study of eight seasons (2010-2018)
}

\author{
Joe W. Cross ${ }^{\mathrm{a}, \mathrm{b}}$, Mark Joy ${ }^{\mathrm{a}, 1}$, Christopher McGee ${ }^{\mathrm{a}, \mathrm{c}}$, Oluwafunmi Akinyemi ${ }^{\mathrm{a}, 1}$, Piers Gatenby ${ }^{\mathrm{a}, \mathrm{b}}$, \\ Simon de Lusignan ${ }^{\mathrm{d}, \mathrm{c}, *}$ \\ ${ }^{a}$ University of Surrey Department of Clinical and Experimental Medicine, University of Surrey, Guildford GU2 7XH, United Kingdom \\ ${ }^{\mathrm{b}}$ The Royal Surrey County Hospital, Egerton Road, Guildford GU2 7XX, United Kingdom \\ ${ }^{\mathrm{c}}$ Royal College of General Practitioners Research and Surveillance Centre, 30 Euston Square, London NW1 2FB, United Kingdom \\ ${ }^{\mathrm{d}}$ University of Surrey Professor of Primary Care and Clinical Informatics, University of Surrey, Guildford GU2 7XH, United Kingdom
}

\section{A R T I C L E I N F O}

\section{Article history:}

Received 29 September 2019

Received in revised form 10 March 2020

Accepted 19 March 2020

Available online 13 April 2020

\section{Keywords:}

Influenza

Adverse events of interest

Medical records systems

Computerised

\begin{abstract}
A B S T R A C T
Background: Influenza contributes significantly to the burden of disease worldwide; the United Kingdom has a policy of vaccination across all ages. Influenza vaccinations are known to be associated with common minor adverse events of interest (AEIs). The European Medicines Agency (EMA) recommends ongoing surveillance of AEIs following influenza vaccination to monitor common and detect infrequent but important AEIs.

Methods: A retrospective cohort study using computerised medical record data from the Royal College of General Practitioners (RCGP) Research and Surveillance Centre (RSC) sentinel network database 2010$2018(\mathrm{~N}=848,375)$. We extracted data about vaccine exposure $(\mathrm{n}=3,121,334)$ and consultations for AEIs within seven days of receiving vaccinations specified by the EMA $(1,488,870$ consultations by 430,029 unique individuals). We used a self-case series design which employs a likelihood estimation method using conditioning of observed adverse events. Such a model assumes non-homogenous Poisson intensity processes for each exposure period and age interval. We compared AEI between QIV and TIV reporting relative incidence (RI) of AEIs. A RI < 1 signified lower AEI rate compared to TIV.

Results: QIV was associated with a RI of AEIs of 1.14 (95\%CI, 1.10-1.18, $\mathrm{p}<0.01)$, though the number of years exposure was limited. By way of contrast, LAIV had a lower rate $0.60(95 \% \mathrm{CI} 0.63-0.68, \mathrm{p}<0.001)$. Cellular manufacture was also associated with a lower rate $0.78(95 \% \mathrm{CI} 0.61-0.99, \mathrm{p}=0.04)$. AEIs varied by season: Rash and musculoskeletal conditions are particularly pronounced in the 2014/15 season and respiratory conditions in 2016/17. In an analysis of all seasons, we found an elevated relative incidence of AEIs of 1.78 (95\%CI, 1.62-1.95) in pregnant women and 1.76 (95\%CI, $1.56-1.99)$ in children under 5 years.

Conclusion: Routine sentinel network data can be used to contrast AEIs between vaccine types and may provide a consistent method of observation of vaccine benefit-risk over time.
\end{abstract}

(C) 2020 The Author(s). Published by Elsevier Ltd. This is an open access article under the CC BY-NC-ND license (http://creativecommons.org/licenses/by-nc-nd/4.0/).

\section{Introduction}

Influenza remains a disease with a high morbidity and mortality burden in developing and developed countries and vaccination is

\footnotetext{
* Corresponding author at: Nuffield Department of Primary Care Health Sciences, University of Oxford, Woodstock Rd, Oxford OX2 6GG, United Kingdom.

E-mail addresses: joecross@surrey.ac.uk (J.W. Cross), mark.joy@phc.ox.ac.uk (M. Joy), c.mcgee@surrey.ac.uk (C. McGee), oluwafunmi.akinyemi@phc.ox.ac.uk (O. Akinyemi), p.gatenby@surrey.ac.uk (P. Gatenby), Simon.delusignan@phc.ox.ac. uk (S. de Lusignan).

1 Present address: Nuffield Department of Primary Care Health Sciences, University of Oxford, Woodstock Rd, Oxford OX2 6GG, United Kingdom.
}

an effective way to reduce the numbers and severity of influenza cases [1]. Seasonal influenza vaccination is an important part of the United Kingdom's public health programme with vaccination across all ages. The UK has a vaccine uptake of over $70 \%$ in adults 65 years and older, with targeted vaccination of high-risk adults, carers, health workers and children [2].

Influenza vaccines composition changes each year based on recommendations from the World Health Organisation (WHO) about the circulating strain and also as new vaccines types are developed. Up to 2013, in the UK, the standard flu vaccines was trivalent, inactivated vaccine (TIV) made up of two influenza A and one influenza B strains [3]. However, since then a quadrivalent inactivated 
vaccine (QIV), which is as trivalent with an additional influenza B strain, had been available to better cover the two globally circulating influenza $B$ lineages [4]. In addition, the use of a live attenuated influenza vaccination (LAIV) for children was introduced during the 2013/14 season in the UK [5]. LAIV products are administered intranasally and consist of intact virus with reduced virulence as opposed to disrupted split virion or subunit vaccines. LAIV is also quadrivalent.

The method of manufacture of influenza vaccines also varies. Currently the majority of seasonal influenza vaccine is produced from virus propagation in fertilised hen eggs, inactivation and purification [6]. This process is resource intensive, slow and poses issues for patients with allergies to egg protein as well as requiring alteration to the viral genome for efficient replication [7]. In contrast, cell culture techniques using monkey (Vero) [8] and dog (Madin-Darby Canine Kidney) [9] epithelial cell lines have fewer contaminants, faster scale-up times, and can be stored frozen in bulk. These advantages are anticipated to lead to a conversion to cell-culture based vaccine production in the future [10]. The 2019/20 flu season will see the first use of cell-based quadrivalent vaccine in the UK [11].

Influenza vaccinations are known to be temporally associated with common minor adverse events of interest (AEIs) as well as distinct adverse reactions such as febrile convulsions [12], Guillain-Barré syndrome [13] and oculo-respiratory syndrome [14]. The monitoring of AEI frequency, type and severity is now a European Medicines Agency (EMA) requirement for Marketing Authorisation Holders (MAHs) producing influenza vaccinations, they are required to produce enhanced safety surveillance data [15]. It is not clear if particular methods of vaccine production or types lead to more AEI than others; and to what extent this varies from season to season.

We carried out this study to identify and describe the population receiving seasonal influenza vaccination over eight flu seasons (between 2010 and 2018). This included reporting the relative incidence rates for AEI occurring following influenza vaccination for eight flu seasons between 2010 and 2018.

We report incidence rates of AEI by: (1) Vaccine manufacturer, (2) The number of viral strains included (trivalent or quadrivalent), (3) Route of vaccine delivery (intramuscular or intranasal) and (4) Manufacturing technology (mammalian cell or fertilized hens egg).

\section{Methods}

\subsection{Study design and participants}

This retrospective cohort study utilised the computerised medical record (CMR) data from the Royal College of General Practitioners (RCGP) Research and Surveillance Centre (RSC), one of Europe's oldest sentinel networks [16]. We used these data to retrospectively calculate the incidence of AEI following seasonal influenza vaccination between the years 2010 and 2018. We have modelled the impact of vaccine delivery route, number of included strains, manufacturing technique, and manufacturer on the incidence of AEI to better understand the factors contributing to influenza vaccine adverse events.

We included the data of all patients who had received a seasonal influenza vaccination in any influenza season (defined as September 1st to April 30th) across the years 2010 to 2018. Patients receiving a vaccine were followed up retrospectively for that influenza season and any occurrence of adverse events of interest (AEI), as specified by the European Medical Agency (EMA) [15], and extracted into a dataset for analysis.

Patients were excluded if they were aged over 100 years old or have attended practices involved in other EMA enhanced surveil- lance schemes [17-19]. Vaccinations using monovalent preparations raised against pandemic influenza were not included in this study.

\subsection{Data sources}

This study used data from the RCGP RSC sentinel network, its prime functions include monitoring of influenza, respiratory and other monitored conditions, and assessing vaccine effectiveness. The RCGP RSC at the time of this study comprised more than 4.9 million patients registered at over 200 general practices across England and is broadly representative of the national population [16]. Clinical encounters are encoded using 5-byte Read or Clinical Terms Version 3 (CTV3) codes entered into a patient's electronic medical record [20]. RCGP RSC practices get feedback about data quality, most recently via a dashboard [21].

\subsection{Vaccine identification}

Details about each vaccination were determined from prescription data, where available, and data entered in the form of a clinical event for influenza vaccination. The process we used was as follows. Firstly, prescription data for a vaccination was used to assign drug name, manufacturer, valency (the number of included viral strains; trivalent or quadrivalent), and administration route. Secondly, batch numbers from prescription data were collated for each drug name and used to assign manufacturer, route, and valency for patients without prescription data. Where both prescription and event data were present we checked for conflicts in any of the assigned fields and conflicting data were removed from the analysed dataset.

\subsection{Variables}

For each patient receiving an influenza vaccination in any influenza season the following data were extracted: age, sex, self-reported ethnicity, vaccination date, index of multiple deprivation (IMD), smoking status, alcohol consumption, vaccine manufacturer, registration date, deregistration date, date of any AEI, and type of AEI

\subsection{Statistical methods}

This study was analysed using a self-controlled case series approach [22,23], often used in investigating adverse events after administration of medications and especially vaccinations. This approach uses each patient as their own control by identifying an exposure period (shortly after vaccination) and baseline (remainder of the observation period) and comparing the frequency of adverse events of interest between them [24]. In this way, all time invariant confounding is controlled for.

For this study the observation period was the first day of September to the last day of April in each of the years 2010 to 2018. The exposure (control) period was defined as starting on the day of vaccine administration (day 0 ). The end day of the exposure period was day 7 for most analyses. When alternative end days are used these are indicated in the relevant sections. To adjust for seasonal variation in the incidence of events of interest our model incorporated a variable representing the month of the year.

All statistical analysis was performed using R 3.4.4 [25] and the packages tidyverse version 1.2.1 [26], SCCS version 1.1 [23], lubridate [27], epitools [28], and tableone [29]. Graphical output was generated using the packages ggplot2 [30] and ggthemes version 3.5.0 [31]. 


\subsection{Ethical considerations}

No patient-identifiable information was made available to researchers. All potentially identifiable data are pseudonymised as close to source as technically feasible and unavailable to researchers, patients who opt out of data sharing (approximately $2 \%$ of the population, do not have their data extracted). All data storage and processing were carried out at the RCGP RSC secure data and analytics hub, University of Surrey. The study was approved by RCGP, and the Health Research Authority/ Medical Research Council tool suggested this was a service evaluation of usual practice study not requiring further ethical review.

\section{Results}

\subsection{Study participants}

848,375 unique individuals were identified between 2010 and 2018 , between them they received 3,121,334 seasonal influenza vaccinations. The flow of patients through this study is shown in Fig. 1. Baseline demographic characteristics of the study participants are shown in Table 1 . Overall, the median age of vaccine recipients was 67 years. This is expected, reflecting the national guidance that patients $>65$ years old be routinely offered influenza vaccination. Most of the participants were of white ethnicity and there was a slight female preponderance throughout the study, probably due to pregnancy. Median Index of Multiple Deprivation was 12.76 and half of the participants had a history of smoking.

The age-sex profile for all unique individuals (Figs. 2a-c) showed a peak at two to four years, representing children who received the live attenuated intranasal vaccine, an increase in female recipients at 20 to 40 years possibly representing vaccination of pregnant women and a sharp increase in update in the mid-60 s representing routine vaccination of the 65 years and over.

The distribution of ethnicity was broadly in agreement with national data, however index of multiple deprivation (IMD, higher scores indicate patients reside in more socioeconomically deprived neighbourhoods) scores were lower in the vaccinated population compared to the national median [32]. Alcohol intake status remained static in the vaccinated population over the course of the study. The proportion of active smokers was lower than the national average but reduced year-on-year in line with national trends [33].

\subsection{Outcome data}

\subsubsection{Vaccine type}

Vaccination route was predominantly intramuscular with $2,462,721$ (78.9\%) cases recorded. Intranasal vaccinations are recorded in significant numbers from 2013/14, coinciding with the introduction of the national live-attenuated vaccination scheme. A total of 215,826 (6.9\%) LAIV were recorded. Valency, the number of included viruses, could be determined in $2,409,908$ (77.2\%) of all cases. Trivalent vaccines formed the bulk of all vaccinations for which valency could be deduced; $2,060,578$ (85.5\% of vaccines with a known composition). From $2014 / 15$ onwards quadrivalent vaccines begin to be recorded as both intramuscular and intranasal formulations. A total of 349,330 ( $14.5 \%$ of vaccines with a known composition) quadrivalent vaccines were identified, of which 206,245 were LAIV and 142,516 intramuscular. A small number of trivalent LAIV (2413) were identified.

\subsection{Adverse events of interest}

A total of $1,488,870$ GP consultations by 430,029 unique individuals ( $50.7 \%$ of all participants) for influenza vaccine surveillance conditions were identified across all years of this study. Of these, 79,260 consultations by 65,141 unique individuals $(7.7 \%$ of all participants) occurred within 7 days of influenza vaccination.

The conditions for which consultation was sought were grouped according to the EMA category of surveillance condition and shown in Table 2. The most common recorded AEI occurring in the week following vaccination were myalgia, cough, rash and headache however we observed AEI in every category, including potentially fatal conditions such as anaphylaxis $(\mathrm{n}=495)$ Table 3 and Guillain-Barré Syndrome $(\mathrm{n}=266)$ Table 4.

A reduction in RI of AEI 7 days after vaccination was observed with Optaflu.

\subsection{Main results}

\subsubsection{Timing of adverse events}

To investigate the timing of adverse events following influenza vaccination we calculated relative incidence rates at -7 to -1 days, 0 to 7 days, 8 to 13 days, and 14 to 44 days relative to the day of vaccination, defined as day 0 (Supplementary Table 1 ).

There is a slight reduction in the RI of events in the 7 days prior to vaccination for the years 2013 to 2018 possibly reflects the "healthy vaccinee" effect whereby patients feeling unwell defer vaccination. The 7 days following vaccination show a consistently elevated RI of between 1.9 and 2.6 in all years studied with an upward trend in the magnitude of this effect. The periods between 8 and 14 days, and 15 and 45 days have RIs fractionally elevated over baseline but to a far lesser degree than in the 0-7 day period.

\subsubsection{Vaccine manufacturer}

The manufacturer of influenza vaccine could be determined for between $24.3 \%$ and $82.2 \%$ of all vaccinations in each season. We identified QIV produced by GSK or Sanofi Pasteur, and TIV produced by BGP, Crucell, GSK Sanofi Pasteur or Seqirus.

The proportion of vaccines for which a manufacturer could be determined increased markedly across the years of the study as a result of improving recording of specific vaccine prescription data and batch numbers (data not shown).

Incidence rates for all AEI in the 7 days following vaccination for each manufacturer showed minimal variation (Table 5) amongst IIV with the notable exception of the GSK vaccine in 2016/17 which shows a threefold increase in adverse events over the rate for all vaccines.

To further investigate this finding, we analysed the breakdown of individual clinical conditions contributing to this increased incidence (Supplementary Fig. 1). As almost all GSK vaccines administered in this year were quadrivalent we limited our analysis to QIV only. Myalgia and cough are the two most common conditions each year for patients receiving GSK vaccines however they are present at higher rates in 2016/17 than otherwise. In addition, several conditions which have previously only been present at low rates are more common in the 2016/17 season; rhinorrhoea, fatigue, headache, and local erythema (see Figs. 3 and 4).

\subsubsection{Valency of vaccine}

To investigate the impact of the valency of influenza vaccines the self-contained case series (SCCS) model incorporating a dummy variable for quadrivalent intramuscular (QIV) and trivalent intramuscular (TIV) vaccines was created. The interaction terms for this model are shown in Table 6 for the years 2015-2018, the only years in which substantial numbers of QIV were administered. Although the overall interaction term was greater than one, indi- 


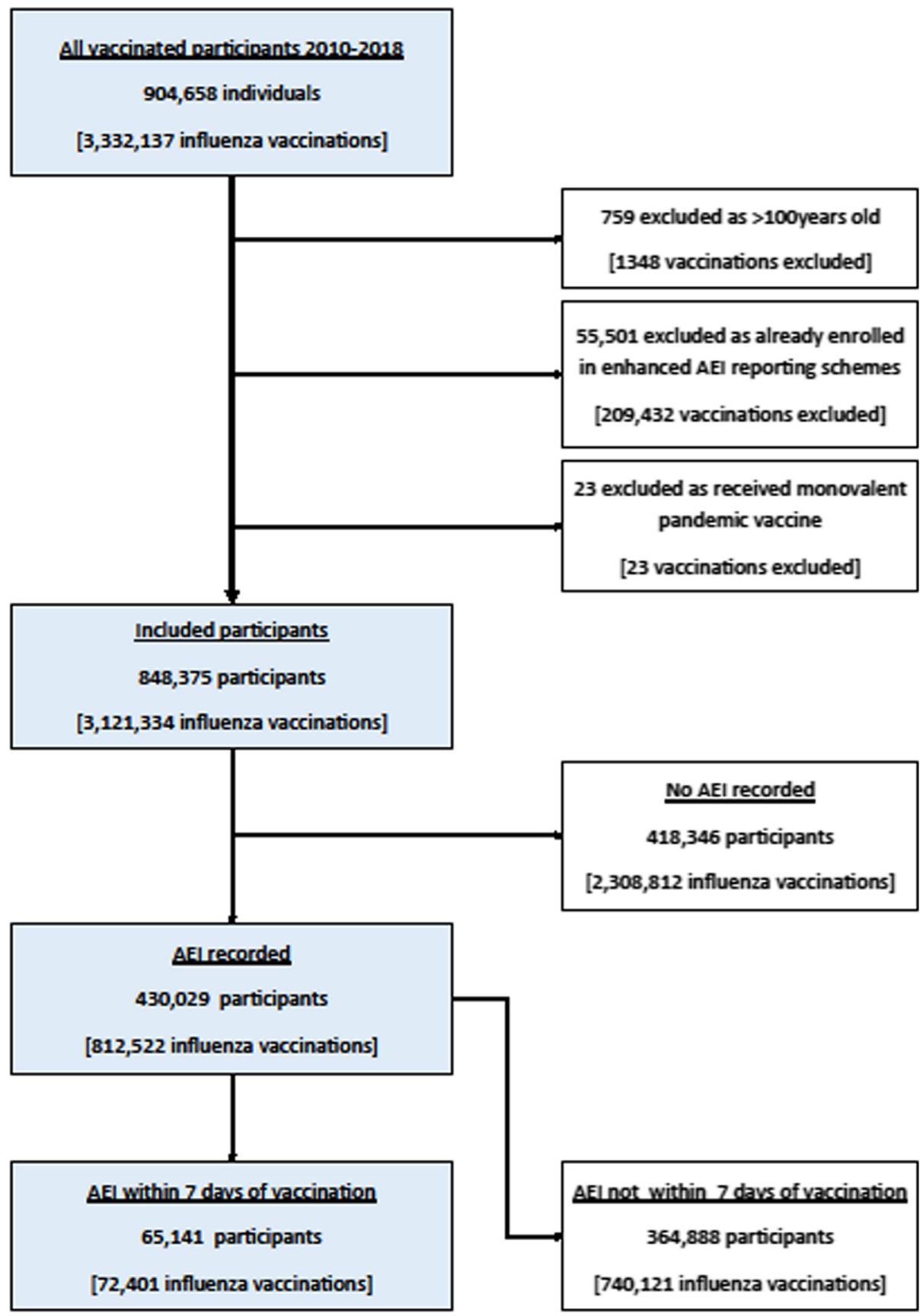

Fig. 1. Schematic of study design.

cating an increased RI with QIV compared to TIV, this effect was almost entirely limited to the 2016/17 season.

The distribution of the AEI experienced by patients was analysed and shows a moderate increase in the incidence of most conditions. Rash and musculoskeletal conditions are particularly pronounced in the 2014/15 season and respiratory conditions in 2016/17.

\subsubsection{Administration route of vaccine}

The impact of administration route, intramuscular or intranasal, was assessed in a similar manner. Intranasal vaccinations were present in this dataset in sufficient numbers for analysis in the years 2013 to 2018 . For all years analysed the interaction term was 0.6-0.7 indicating a lower incidence of AEI resulting in GP consultation than influenza vaccination as a whole.
As the recipients of LAIV are overwhelmingly children in the age range 2-4 years old who could reasonably be expected to have different rates of presentation to GPs compared to adults we repeated this analysis including only patients under the age of 5 . The overall RI for this population was $1.76(1.56-1.99)$ with an interaction term for LAIV of $0.60(0.52-0.68)$ indicating that the lower rate of AEI was not a function of the age of the vaccine recipients (Table 7).

The distribution of AEI types was also examined. LAIV were associated with increased incidence of fevers, rashes, and respiratory symptoms. Musculoskeletal and constitutional symptoms (drowsiness, fatigue, irritability, malaise, and headache) were seen less frequently in patients receiving LAIV Figs. $3 a$ and $3 b$. 
Table 1

Demographic characteristics of seasonal influenza vaccine recipients from RCGP RSC dataset.

\begin{tabular}{|c|c|c|c|c|c|c|c|c|c|}
\hline & $2010 / 11$ & $2011 / 12$ & $2012 / 13$ & $2013 / 14$ & $2014 / 15$ & $2015 / 16$ & $2016 / 17$ & $2017 / 18$ & All years \\
\hline Participants & 335,943 & 355,281 & 373,138 & 410,171 & 435,478 & 449,643 & 466,866 & 505,617 & $3,332,137$ \\
\hline $\begin{array}{l}\text { Age (median } \\
[\mathrm{IQR}])\end{array}$ & $68[56,77]$ & $68[56,77]$ & $68[56,76]$ & $67[51,76]$ & $67[49,76]$ & $67[46,75]$ & $66[44,75]$ & $66[41,75]$ & $67[50,76]$ \\
\hline \multicolumn{10}{|l|}{ Sex $(\%)$} \\
\hline Male & $\begin{array}{l}150,354 \\
(44 \cdot 8)\end{array}$ & $\begin{array}{l}158,739 \\
(44 \cdot 7)\end{array}$ & $\begin{array}{l}166,411 \\
(44 \cdot 6)\end{array}$ & $\begin{array}{l}184,738 \\
(45 \cdot 0)\end{array}$ & $\begin{array}{l}196,063 \\
(45 \cdot 0)\end{array}$ & $\begin{array}{l}202,431 \\
(45 \cdot 0)\end{array}$ & $\begin{array}{l}210,996 \\
(45 \cdot 2)\end{array}$ & $\begin{array}{l}228,963 \\
(45 \cdot 3)\end{array}$ & $\begin{array}{l}1,498,695 \\
(45 \cdot 0)\end{array}$ \\
\hline Female & $\begin{array}{l}185,589 \\
(55 \cdot 2)\end{array}$ & $\begin{array}{l}196,542 \\
(55 \cdot 3)\end{array}$ & $\begin{array}{l}206,727 \\
(55 \cdot 4)\end{array}$ & $\begin{array}{l}225,433 \\
(55 \cdot 0)\end{array}$ & $\begin{array}{l}239,415 \\
(55 \cdot 0)\end{array}$ & $\begin{array}{l}247,212 \\
(55 \cdot 0)\end{array}$ & $\begin{array}{l}255,870 \\
(54 \cdot 8)\end{array}$ & $\begin{array}{l}276,654 \\
(54 \cdot 7)\end{array}$ & $\begin{array}{l}1,833,442 \\
(55 \cdot 0)\end{array}$ \\
\hline \multicolumn{10}{|l|}{ Ethnicity (\%) } \\
\hline White & $\begin{array}{l}247,408 \\
(73 \cdot 6)\end{array}$ & $\begin{array}{l}263,232 \\
(74 \cdot 1)\end{array}$ & $\begin{array}{l}277,476 \\
(74 \cdot 4)\end{array}$ & $\begin{array}{l}303,741 \\
(74 \cdot 1)\end{array}$ & $\begin{array}{l}319,213 \\
(73 \cdot 3)\end{array}$ & $\begin{array}{l}328,739 \\
(73 \cdot 1)\end{array}$ & $\begin{array}{l}339,537 \\
(72 \cdot 7)\end{array}$ & $\begin{array}{l}366,177 \\
(72 \cdot 4)\end{array}$ & $\begin{array}{l}2,445,523 \\
(73 \cdot 4)\end{array}$ \\
\hline Asian & $11,465(3.4)$ & $12,815(3.6)$ & $14,485(3.9)$ & $16,772(4 \cdot 1)$ & $18,721(4 \cdot 3)$ & $20,319(4.5)$ & $21,277(4 \cdot 6)$ & $22,930(4 \cdot 5)$ & $138,784(4 \cdot 2)$ \\
\hline Black & $4984(1.5)$ & $5483(1.5)$ & $6294(1.7)$ & $7240(1.8)$ & $8052(1.8)$ & 8507 (1.9) & $9220(2.0)$ & $9707(1.9)$ & $59,487(1.8)$ \\
\hline Mixed & $1487(0.4)$ & $1575(0.4)$ & $1870(0.5)$ & $2479(0.6)$ & $2983(0.7)$ & $3341(0.7)$ & $3674(0.8)$ & $4295(0.8)$ & $21,704(0.7)$ \\
\hline Other & $1091(0 \cdot 3)$ & $1279(0.4)$ & $1400(0.4)$ & $1764(0.4)$ & $1998(0.5)$ & $2301(0.5)$ & $2379(0.5)$ & $2692(0.5)$ & $14,904(0.4)$ \\
\hline Missing data & $69,508(20 \cdot 7)$ & $70,897(20 \cdot 0)$ & $71,613(19 \cdot 2)$ & $78,175(19 \cdot 1)$ & $84,511(19.4)$ & $86,436(19 \cdot 2)$ & $90,779(19.4)$ & $99,816(19.7)$ & $\begin{array}{l}651,735 \\
(19 \cdot 6)\end{array}$ \\
\hline $\begin{array}{l}\text { IMD (median } \\
\text { [IQR]) }\end{array}$ & $\begin{array}{l}12 \cdot 74[7 \cdot 34 \\
22 \cdot 61]\end{array}$ & $\begin{array}{l}12 \cdot 78[7 \cdot 34 \\
22 \cdot 59]\end{array}$ & $\begin{array}{l}12 \cdot 79[7 \cdot 34, \\
22 \cdot 82]\end{array}$ & $\begin{array}{l}12 \cdot 76[7 \cdot 31 \\
22 \cdot 79]\end{array}$ & $\begin{array}{l}12 \cdot 69[7 \cdot 28 \\
22 \cdot 78]\end{array}$ & $\begin{array}{l}12 \cdot 75[7 \cdot 26 \\
22 \cdot 86]\end{array}$ & $\begin{array}{l}12 \cdot 76[7 \cdot 27 \\
22 \cdot 86]\end{array}$ & $\begin{array}{l}12 \cdot 78[7 \cdot 27 \\
22 \cdot 87]\end{array}$ & $\begin{array}{l}12 \cdot 76[7 \cdot 31 \\
22 \cdot 82]\end{array}$ \\
\hline \multicolumn{10}{|c|}{ Smoking status (\%) } \\
\hline Active smoker & $61,866(18.4)$ & $68,001(19 \cdot 1)$ & $68,582(18.4)$ & $57,490(14.0)$ & $53,868(12 \cdot 4)$ & $51,545(11.5)$ & $52,143(11 \cdot 2)$ & $54,045(10 \cdot 7)$ & $\begin{array}{l}467,540 \\
(14 \cdot 0)\end{array}$ \\
\hline Ex-smoker & $\begin{array}{l}148,616 \\
(44 \cdot 2)\end{array}$ & $\begin{array}{l}156,821 \\
(44 \cdot 1)\end{array}$ & $\begin{array}{l}168,280 \\
(45 \cdot 1)\end{array}$ & $\begin{array}{l}187,395 \\
(45 \cdot 7)\end{array}$ & $\begin{array}{l}198,072 \\
(45 \cdot 5)\end{array}$ & $\begin{array}{l}200,801 \\
(44 \cdot 7)\end{array}$ & $\begin{array}{l}206,311 \\
(44 \cdot 2)\end{array}$ & $\begin{array}{l}218,870 \\
(43 \cdot 3)\end{array}$ & $\begin{array}{l}1,485,166 \\
(44 \cdot 6)\end{array}$ \\
\hline Non-smoker & $\begin{array}{l}105,733 \\
(31 \cdot 5)\end{array}$ & $\begin{array}{l}112,097 \\
(31 \cdot 6)\end{array}$ & $\begin{array}{l}117,191 \\
(31 \cdot 4)\end{array}$ & $\begin{array}{l}123,800 \\
(30 \cdot 2)\end{array}$ & $\begin{array}{l}130,664 \\
(30 \cdot 0)\end{array}$ & $\begin{array}{l}134,071 \\
(29 \cdot 8)\end{array}$ & $\begin{array}{l}138,010 \\
(29 \cdot 6)\end{array}$ & $\begin{array}{l}148,975 \\
(29 \cdot 5)\end{array}$ & $\begin{array}{l}1,010,541 \\
(30 \cdot 3)\end{array}$ \\
\hline Missing data & $19,728(5 \cdot 9)$ & $18,362(5 \cdot 2)$ & $19,085(5 \cdot 1)$ & $41,486(10 \cdot 1)$ & $52,874(12 \cdot 1)$ & $63,226(14 \cdot 1)$ & $70,402(15 \cdot 1)$ & $83,727(16 \cdot 6)$ & $\begin{array}{l}368,890 \\
(11 \cdot 1)\end{array}$ \\
\hline \multicolumn{10}{|c|}{ Alcohol intake (\%) } \\
\hline Non-drinker & $25,085(7.5)$ & $27,204(7 \cdot 7)$ & $27,767(7.4)$ & $29,002(7 \cdot 1)$ & $31,504(7 \cdot 2)$ & $32,678(7 \cdot 3)$ & $33,966(7 \cdot 3)$ & $34,935(6 \cdot 9)$ & $242,141(7 \cdot 3)$ \\
\hline Safe & $40,027(11.9)$ & $45,193(12 \cdot 7)$ & $45,526(12 \cdot 2)$ & $47,929(11 \cdot 7)$ & $46,496(10 \cdot 7)$ & $45,199(10 \cdot 1)$ & $43,228(9 \cdot 3)$ & $45,030(8.9)$ & $\begin{array}{l}358,628 \\
(10 \cdot 8)\end{array}$ \\
\hline Hazardous & $44,573(13 \cdot 3)$ & $49,574(14.0)$ & $53,078(14 \cdot 2)$ & $56,182(13 \cdot 7)$ & $55,458(12 \cdot 7)$ & $55,655(12 \cdot 4)$ & $56,461(12 \cdot 1)$ & $60,222(11.9)$ & $\begin{array}{l}431,203 \\
(12 \cdot 9)\end{array}$ \\
\hline Alcoholism & $4986(1.5)$ & $5829(1.6)$ & $6188(1.7)$ & $6645(1.6)$ & $6956(1.6)$ & $7104(1.6)$ & $7421(1.6)$ & $7939(1.6)$ & $53,068(1.6)$ \\
\hline Missing data & $\begin{array}{l}221,272 \\
(65 \cdot 9)\end{array}$ & $\begin{array}{l}227,481 \\
(64 \cdot 0)\end{array}$ & $\begin{array}{l}240,579 \\
(64 \cdot 5)\end{array}$ & $\begin{array}{l}270,413 \\
(65 \cdot 9)\end{array}$ & $\begin{array}{l}295,064 \\
(67 \cdot 8)\end{array}$ & $\begin{array}{l}309,007 \\
(68 \cdot 7)\end{array}$ & $\begin{array}{l}325,790 \\
(69 \cdot 8)\end{array}$ & $\begin{array}{l}357,491 \\
(70 \cdot 7)\end{array}$ & $\begin{array}{l}2,247,097 \\
(67 \cdot 4)\end{array}$ \\
\hline
\end{tabular}

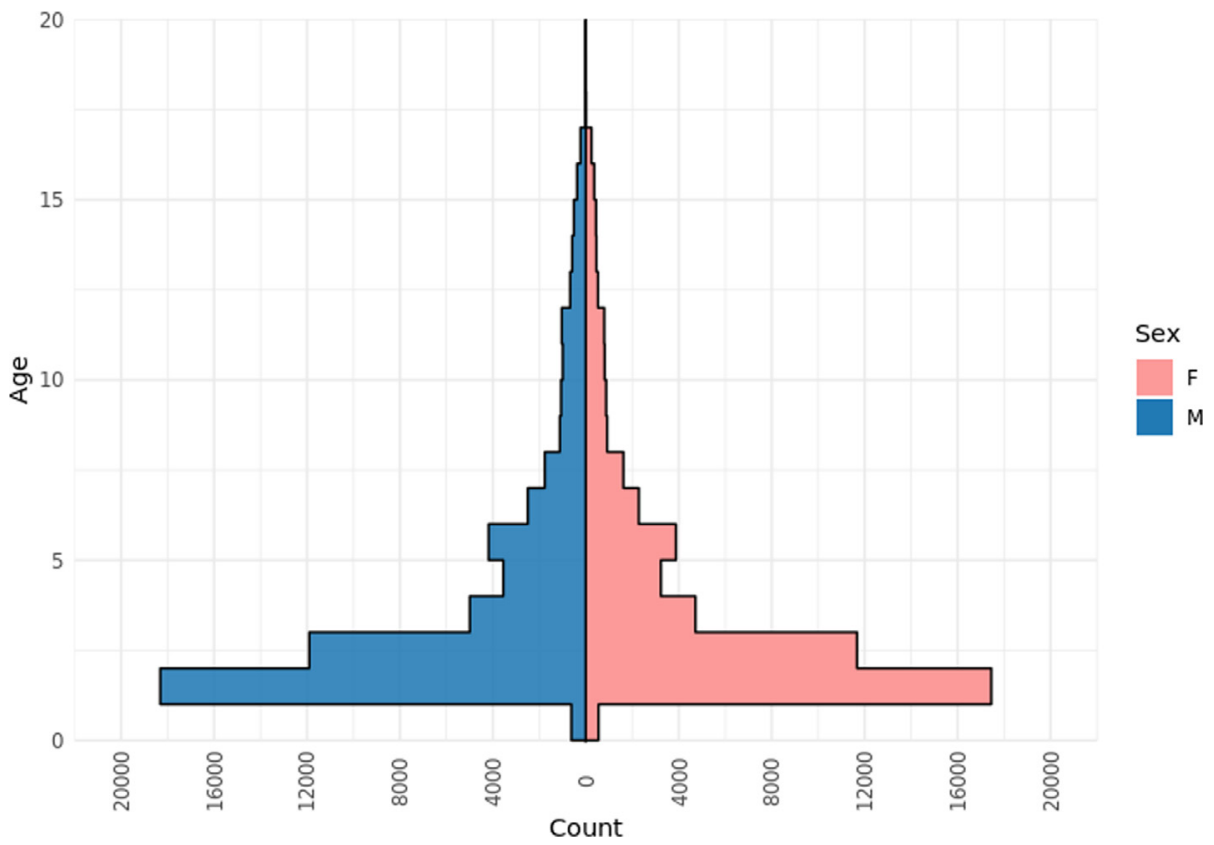

Fig. 2a. Age-sex profile for LAIV recipients in the RCGP RSC network. 


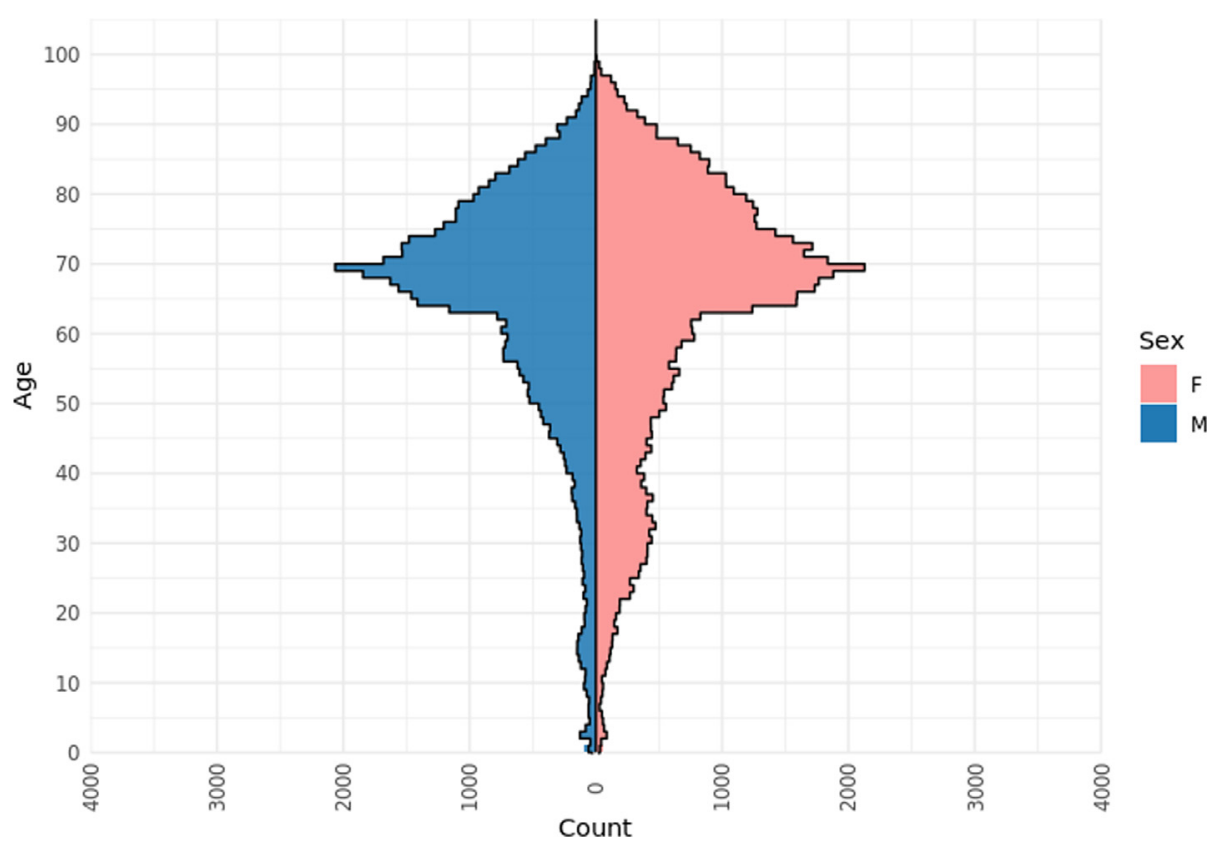

Fig. 2b. Age-sex profile for QIV recipients in the RCGP RSC network.

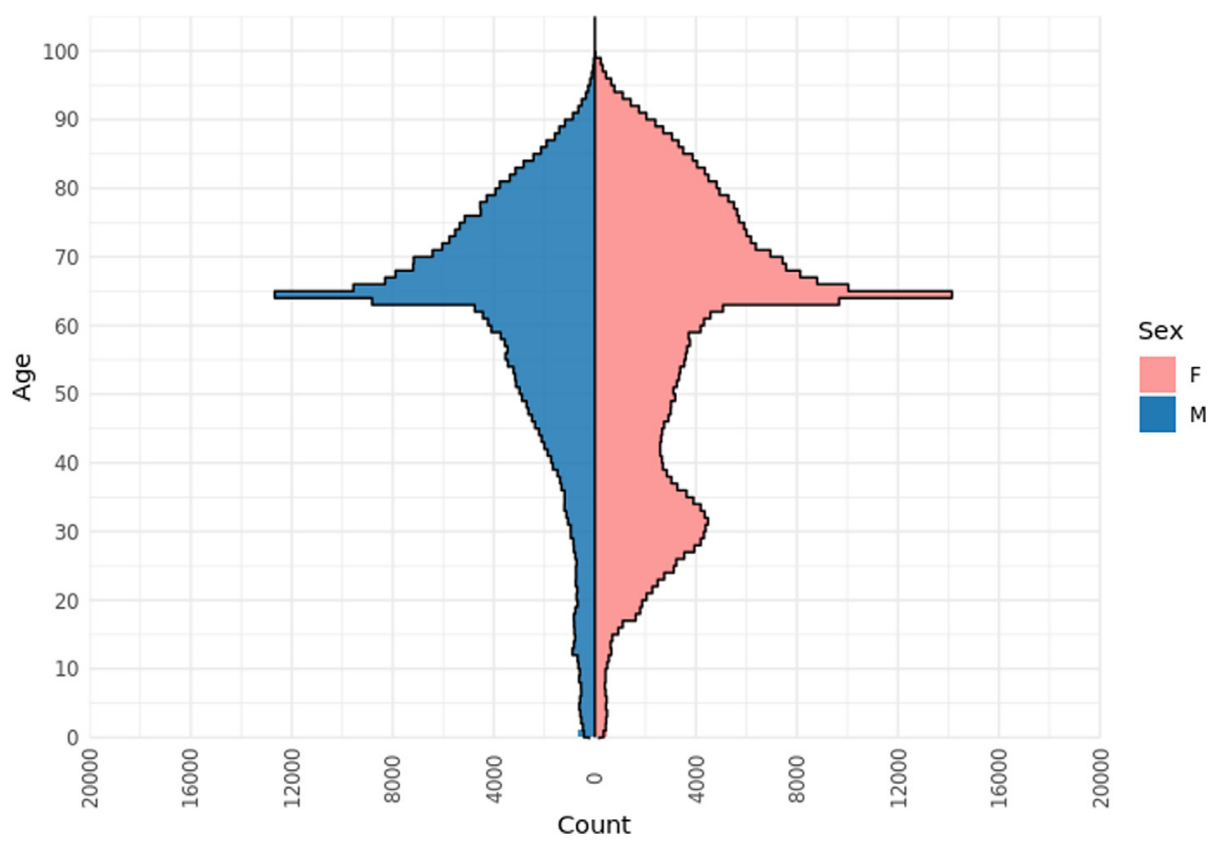

Fig. 2c. Age-sex profile for TIV recipients in the RCGP RSC network.

\subsection{Manufacturing method}

Small numbers of mammalian cell vaccines were used in the period of this study, however there were sufficient numbers in the 2013-2015 seasons to analyse compared to egg-based preparations (4010 vaccinations total, all Optaflu (Seqirus) brand). The interaction term for mammalian cell vaccine was 0.78 (0.61 0.99) overall, indicating a lower incidence of AEI within 7 days of vaccination in this patient group Table 8 . There were insufficient numbers of mammalian cell vaccines to perform a breakdown of the types of AEI experienced.

\subsection{Pregnancy}

There was a greater number of females in the vaccinated population, reflecting the recommendation to give flu immunisations to pregnant women. This group also had an elevated relative incidence of AEIs of 1.78 (1.62-1.95). 
Table 2

Total number of reported events across all influenza seasons and within 7 days of vaccination for 2010 to 2018 .

\begin{tabular}{|c|c|c|c|c|c|c|c|}
\hline \multirow[t]{2}{*}{ AEI group } & \multirow[t]{2}{*}{ AEI } & \multicolumn{2}{|c|}{ Within influenza season } & \multicolumn{2}{|c|}{$\begin{array}{l}\text { Within } 7 \text { days of } \\
\text { vaccination }\end{array}$} & \multirow{2}{*}{$\begin{array}{l}\text { Rates within } 7 \text { days } \\
\text { vaccination } \\
\text { (rate per person week) }\end{array}$} & \multirow{2}{*}{$\begin{array}{l}\text { Proportion of AEI in risk period } \\
\text { Total within } 7 \text { days/Total within } \\
\text { influenza season }\end{array}$} \\
\hline & & $\begin{array}{l}\text { Total } \\
\text { events }\end{array}$ & $\begin{array}{l}\text { Unique } \\
\text { individuals }\end{array}$ & $\begin{array}{l}\text { Total } \\
\text { events }\end{array}$ & $\begin{array}{l}\text { Unique } \\
\text { individuals }\end{array}$ & & \\
\hline \multirow[t]{5}{*}{ Fever } & Fever (unspecified) & 35,959 & 25,934 & 1360 & 1304 & 0.1489921 & 0.03782085 \\
\hline & Fever (mild) & 32,407 & 28,092 & 753 & 745 & 0.1443912 & 0.02323572 \\
\hline & Fever (moderate) & 4650 & 4458 & 86 & 86 & 0.1428571 & 0.01849462 \\
\hline & Fever (high) & 671 & 664 & 12 & 12 & 0.1428571 & 0.01788376 \\
\hline & Total & 73,687 & 59,148 & 2211 & 2147 & 0.1471156 & 0.03000529 \\
\hline \multirow[t]{5}{*}{ Gastrointestinal } & Decreased appetite & 7504 & 5421 & 425 & 402 & 0.1510306 & 0.05663646 \\
\hline & Diarrhoea & 82,789 & 49,050 & 3374 & 3099 & 0.155534 & 0.04075421 \\
\hline & Nausea & 22,955 & 14,659 & 1075 & 998 & 0.1538792 & 0.04683076 \\
\hline & Vomiting & 31,811 & 21,978 & 1184 & 1081 & 0.1564689 & 0.03721983 \\
\hline & Total & 145,059 & $\mathbf{9 1 , 1 0 8}$ & 6058 & 5580 & 0.616913 & 0.04176232 \\
\hline \multirow[t]{6}{*}{ Constitutional } & Drowsiness & 2071 & 1597 & 107 & 103 & 0.148405 & 0.05166586 \\
\hline & Fatigue & 47,997 & 30,260 & 3144 & 2913 & 0.1541857 & 0.06550409 \\
\hline & Irritability & 942 & 614 & 69 & 66 & 0.1493506 & 0.07324841 \\
\hline & Malaise & 35,186 & 23,511 & 1432 & 1332 & 0.1535822 & 0.040698 \\
\hline & Headache & 94,690 & 47,756 & 5329 & 4870 & 0.1563215 & 0.05627838 \\
\hline & Total & 180,886 & 103,738 & 10,081 & 9284 & 0.761845 & 0.05573123 \\
\hline Local symptoms & Erythema & 142 & 137 & 78 & 76 & 0.1466165 & 0.54929577 \\
\hline \multirow[t]{3}{*}{ Musculoskeletal } & Arthropathy & 4197 & 2968 & 258 & 250 & 0.1474286 & 0.06147248 \\
\hline & Myalgia & 296,321 & 139,099 & 17,705 & 16,267 & 0.1554857 & 0.05974939 \\
\hline & Total & 300,518 & 142,067 & 17,963 & 16,517 & 0.302914 & 0.05977346 \\
\hline \multirow[t]{5}{*}{ Neurological } & $\begin{array}{l}\text { Guillain-Barré } \\
\text { syndrome (GBS) }\end{array}$ & 266 & 74 & 10 & 8 & 0.1785714 & 0.03759398 \\
\hline & Tremor & 8218 & 5023 & 473 & 444 & 0.1521879 & 0.05755658 \\
\hline & Seizure/convulsion & 7168 & 3877 & 260 & 234 & 0.1587302 & 0.03627232 \\
\hline & Bell's palsy & 2460 & 1154 & 119 & 108 & 0.1574074 & 0.04837398 \\
\hline & Total & 18,112 & 10,128 & 862 & 794 & 0.646897 & 0.04759276 \\
\hline Rash & Rash & 123,934 & 77,294 & 6992 & 6619 & 0.1509076 & 0.05641713 \\
\hline \multirow{10}{*}{$\begin{array}{l}\text { Respiratory and } \\
\text { coryzal }\end{array}$} & Conjunctivitis & 54,938 & 40,814 & 2734 & 2635 & 0.1482245 & 0.04976519 \\
\hline & Coryza & 8700 & 7455 & 521 & 508 & 0.1465129 & 0.05988506 \\
\hline & Cough & 407,017 & 191,048 & 21,655 & 19,681 & 0.1571857 & 0.05320417 \\
\hline & Epistaxis & 21,588 & 13,449 & 930 & 862 & 0.1541266 & 0.04307949 \\
\hline & Hoarseness & 10,156 & 6761 & 587 & 558 & 0.1502816 & 0.05779835 \\
\hline & Nasal congestion & 27,591 & 19,809 & 1823 & 1770 & 0.1471348 & 0.06607227 \\
\hline & Oropharyngeal pain & 52,272 & 38,400 & 2270 & 2174 & 0.1491655 & 0.04342669 \\
\hline & Rhinorrhoea & 4269 & 3567 & 336 & 333 & 0.1441441 & 0.07870696 \\
\hline & Wheeze & 29,189 & 20,060 & 2464 & 2358 & 0.1492791 & 0.08441536 \\
\hline & Total & 615,720 & 341,363 & 33,320 & 30,879 & 1.346055 & 0.05411551 \\
\hline \multirow[t]{4}{*}{ Hypersensitivity } & Anaphylaxis & 495 & 495 & 32 & 29 & 0.1576355 & 0.06464646 \\
\hline & Facial swelling & 2505 & 1918 & 110 & 101 & 0.155587 & 0.04391218 \\
\hline & $\begin{array}{l}\text { Hypersensitivity } \\
\text { Reactions }\end{array}$ & 10,114 & 8111 & 798 & 7630.1494102 & 0.1494102 & 0.07890053 \\
\hline & Total & 13,114 & 10,524 & 940 & 893 & 0.462633 & 0.07167912 \\
\hline
\end{tabular}

Table 3

Rates of Anaphylactic reactions by vaccine type $(n=495)$.

\begin{tabular}{llll}
\hline & IIV & LAIV & Unknown route \\
\hline Quadrivalent & 16 & 0 & 250 \\
Trivalent & 229 & 0 &
\end{tabular}

IIV: inactivated influenza vaccine; LAIV: live attenuated influenza vaccine

\section{Discussion}

\subsection{Key results}

We demonstrate that seasonal influenza vaccination is associated with a variable incidence of adverse events. The vaccine manufacturer, number of included viruses, the administration route, and the method used to create the vaccine all affect the incidence of AEI. AEI overwhelmingly occur within 7 days of vaccination, although a small detectable increase over baseline incidence was apparent at 14 and 45 days in some years analysed. Additionally, a small preceding "healthy vaccinee" effect was apparent in the week preceding vaccination [34].
The influence of manufacturer on the RI of AEI in the 7 days following vaccination was generally static, although a general upward trend was seen from 2010 to 2018. Overall, patients presented to their GP with conditions associated with influenza vaccination more than twice as often in the 7 days following receipt of the vaccine compared to the rest of the influenza season. Greater recognition of this, and any particular pattern related to a particular vaccine or season, could be used to reassure patients presenting to primary care.

LAIV vaccines, which are delivered intranasally, produced a different pattern of adverse events from intramuscular vaccinations. Respiratory symptoms were more common, which presumably reflects the mechanism of delivery, alongside significantly increased rates of fever and mildly increased rates of rash. In contrast, markedly reduced rates of musculoskeletal and constitutional symptoms such as malaise and fatigue may represent the more localised impact of an aerosolised preparation. The RI of AEI following immunisation with LAIV was lower than that with IIV by $30-40 \%$ (interaction terms of $0.6-0.7$ ). This effect was pre- 


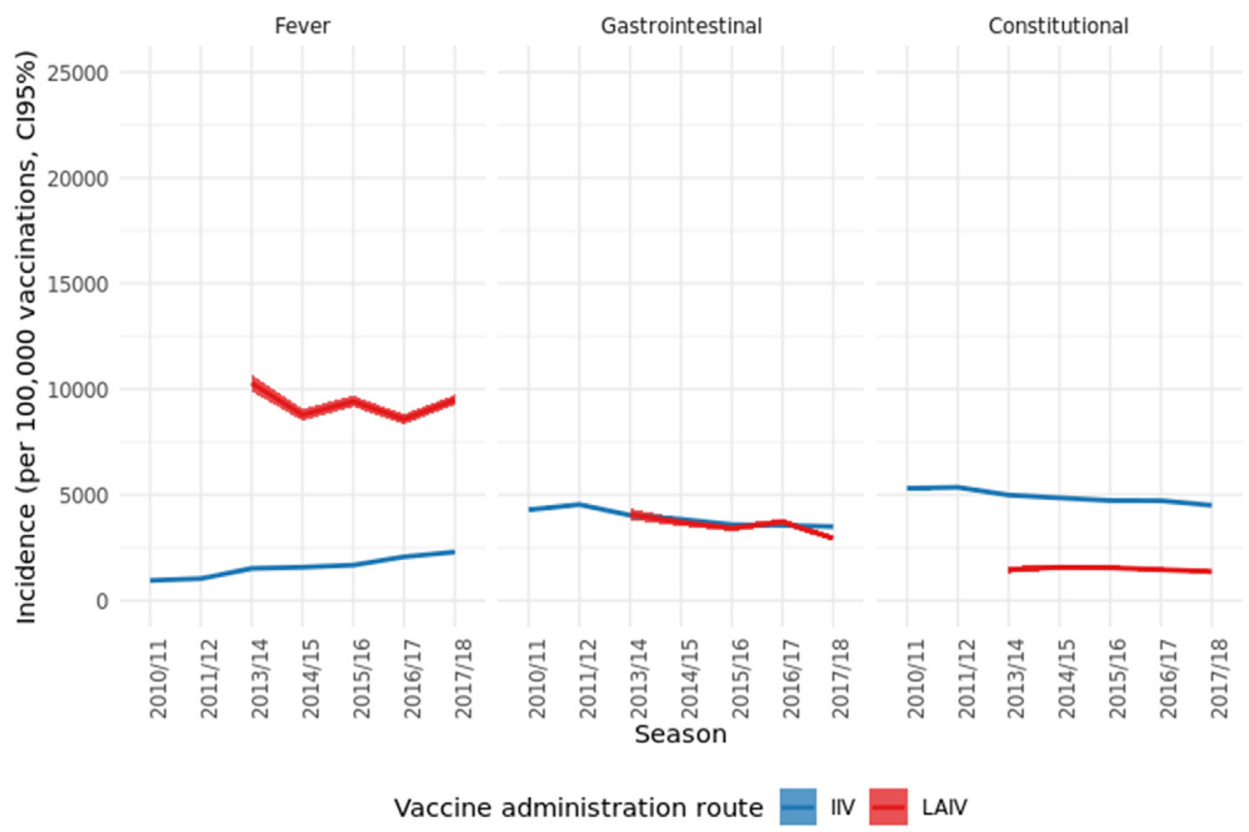

Fig. 3a. Incidence of AEI compared between LAIV and IIV (including ccIIV) vaccines.

served when analysing only under 5 year olds and therefore is not an effect of the age of the LAIV receiving population.

QIV were associated with more AEI when compared to TIV with our model. This effect appeared to be a relatively uniform increase in all AEI groups although musculoskeletal, rash, and respiratory conditions were more prominently increased than other classes of AEI in some seasons. This generalised increase in AEI may represent the higher antigenic load that current quadrivalent vaccines carry ( $60 \mu \mathrm{g}$ vs. $45 \mu \mathrm{g}$ haemagglutinin) as has been suggested in studies of high-dose influenza vaccine [35,36]. Although there have been licenced $27 \mu \mathrm{g}$ preparations on the UK market between 2010 and 2018 they do not appear in sufficient numbers in this dataset to allow for a dose-response analysis of antigenic load.
Optaflu, and similar mammalian cell prepared influenza vaccines have only been used in small numbers in the United Kingdom. Despite this we were able to show a reduction in the RI of AEI in the 7 days following vaccination in patients receiving this vaccine product. Mammalian cell vaccines benefit from not requiring genetic modification of the seed virus in order to allow propagation. Additionally, virus raised in hen eggs contains nonmammalian antigens, such as ovalbumin, which would be expected to induce a greater immune reaction than mammalian equivalents. Further, practices who ordered small numbers of the cellular vaccine to give to those with egg-allergy, who are plausibly a more allergic group.

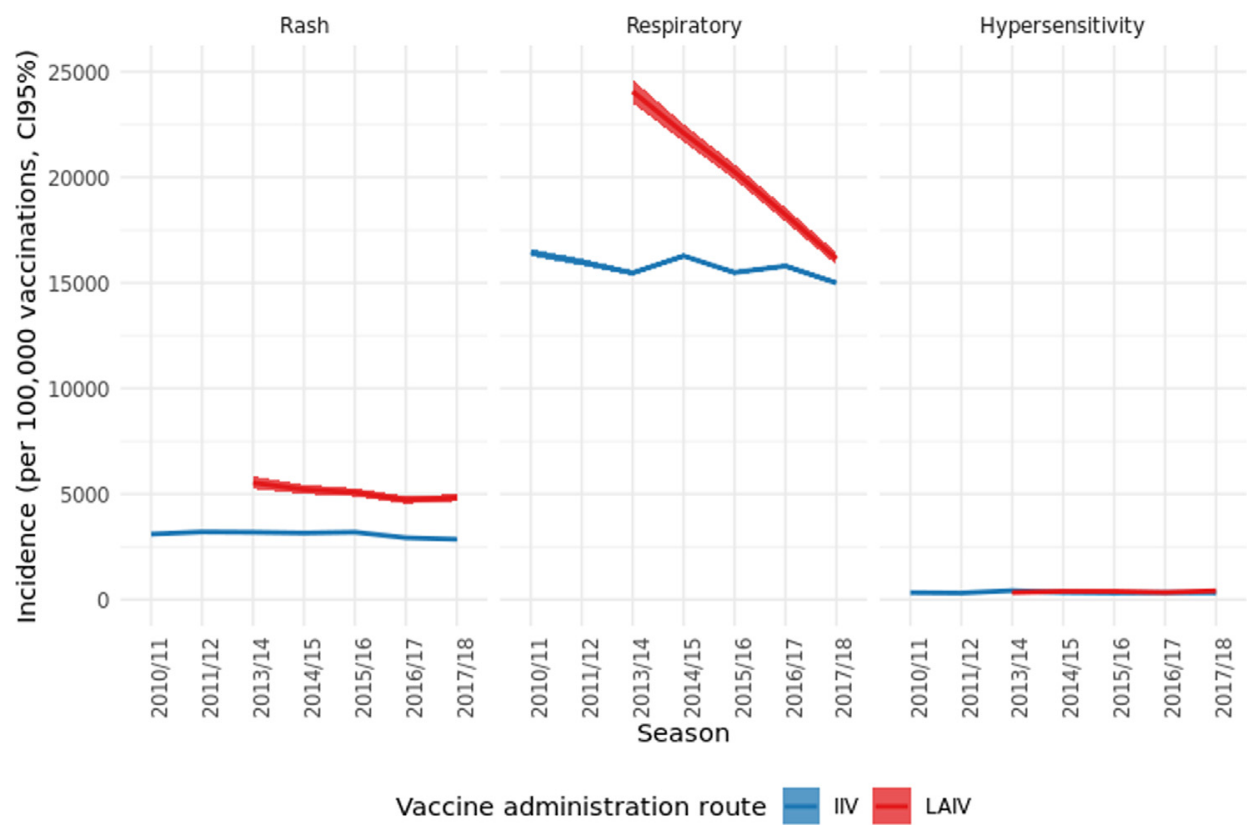

Fig. 3b. Incidence of AEI compared between LAIV and IIV (including ccIIV) vaccines 


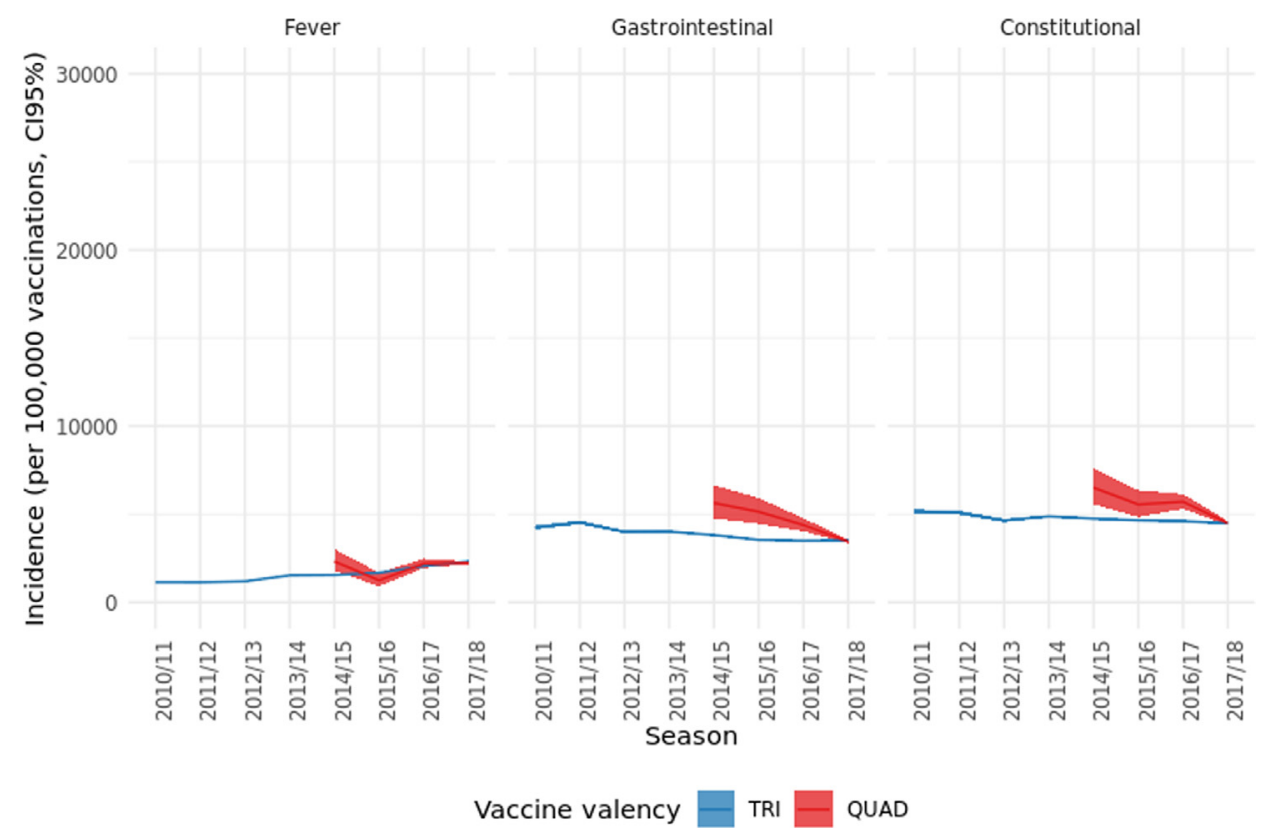

Fig. 4a. Incidence of AEI between quadrivalent and trivalent IIV (including ccIIV) vaccines.

Marked differences between vaccine manufacturers were seen for only a single manufacturer in a single season - GSK vaccines in 2016/17. Analysis of the type of reaction in this season showed an increase in common complaints such as myalgia and cough but also other respiratory symptoms not seen in previous years. The cause of this apparently isolated increase in respiratory AEI is unclear from this data although the 2016/17 season vaccinations did include the A/Hong Kong/4801. Interestingly, we did not find any signal about differences in AEIs from the enhanced surveillance we conducted for GSK in that year. The practices who took part were excluded from this analysis as we felt they might have increased their AEI awareness and recording [37]. It is possible that the EMA goals might be better achieved through systematic data collection across sentinel networks.

\subsection{Strengths and limitations}

RCGP RSC is an established sentinel system, and practices receive feedback about data quality. Practices whose data does not meet a quality threshold are not included in our report. However, data in the RCGP RSC sentinel network is gathered from GP consultations and therefore requires patients to seek medical attention in order for a potential AEI to be recorded. Many of the more common AEI are self-limiting and, to a certain extent, expected by patients receiving the vaccine making their presentation for minor AEI less likely. For example, we are aware from our other studies to detect AEI that local effects of a vaccine were not reported to GPs but only detected through the addition of a questionnaire. Not all vaccines have brand specific data, and influenza

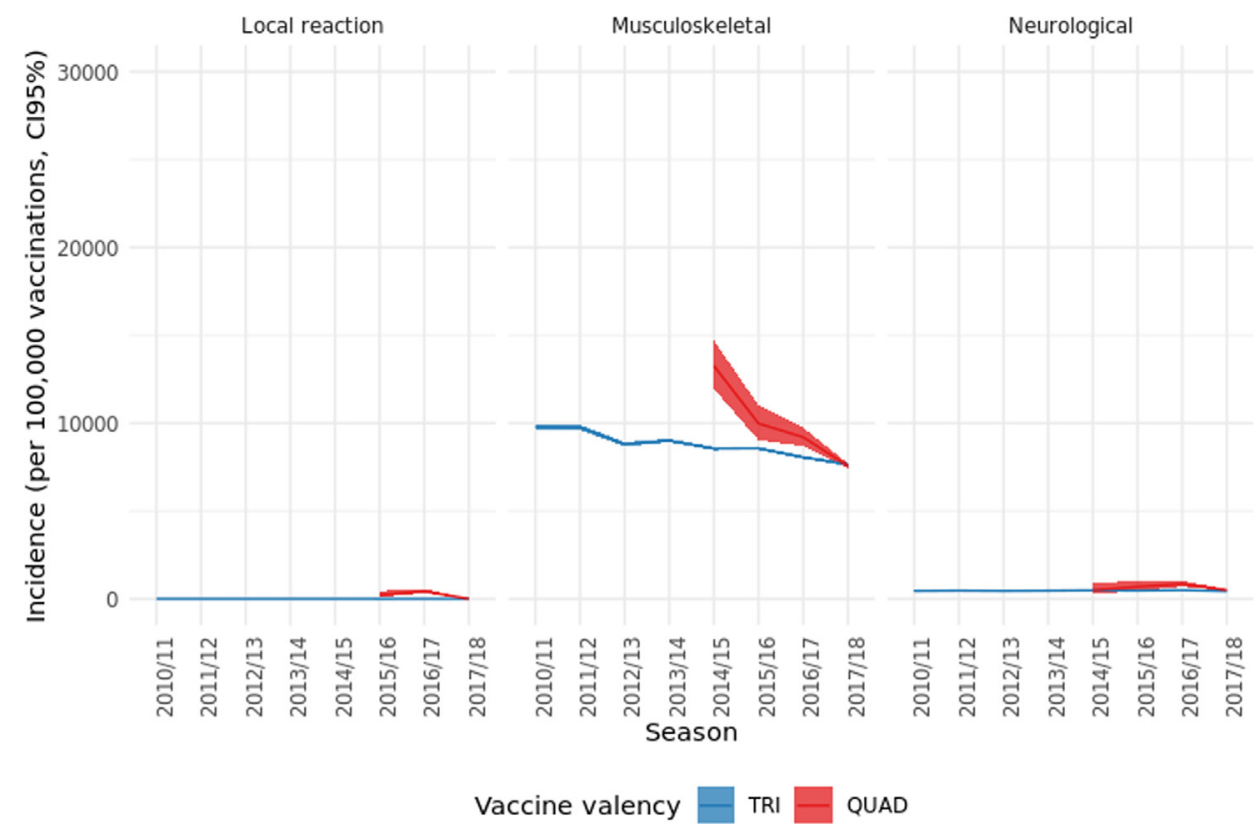

Fig. 4b. Incidence of AEI compared between quadrivalent and trivalent IIV (including ccIIV) vaccines. 


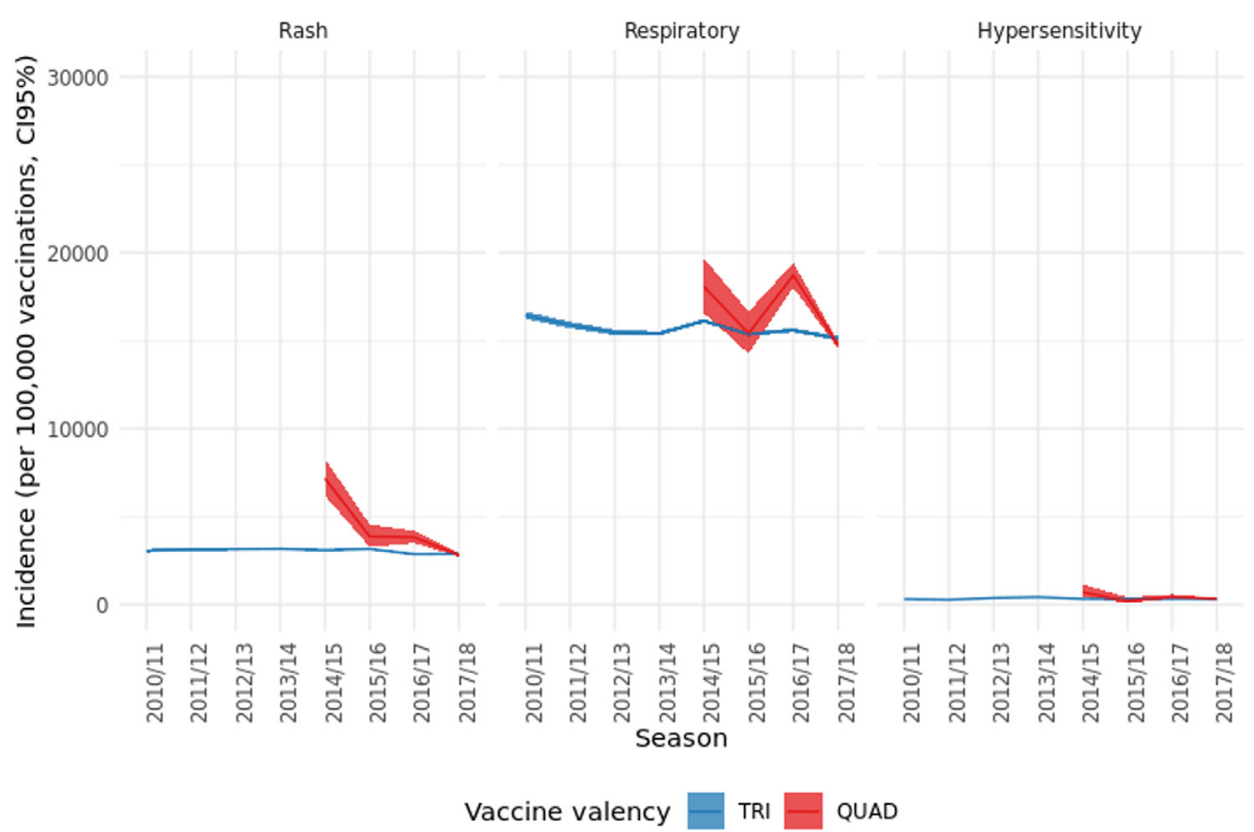

Fig. 4c. Incidence of AEI compared between quadrivalent and trivalent IIV (including ccIIV) vaccines.

Table 4

Rates of Guillain Barré Syndrome by vaccine type $(\mathrm{n}=266)$.

\begin{tabular}{llll}
\hline & IIV & LAIV & Unknown \\
\hline Quadrivalent & 2 & 0 & 135 \\
Trivalent & 129 & 0 & \\
\hline
\end{tabular}

IIV: inactivated influenza vaccine; LAIV: live attenuated influenza vaccine

immunisations not carried out by a GP often have less information recorded [38].

The self-controlled case series method (SCCS) employs a conditional Poisson regression model where conditioning is based on the number of observed events per individual; the method therefore utilises cases only. These models perform well with large or medium-sized case samples. In studies where the (adverse) events of interest are rare, power size calculations are important, whilst some events of interest in this study are relatively rare (e.g. high Fever, irritability, Erythema, Guillain-Barré syndrome, Anaphylaxis), we argue that most are not. If rarity implies that effects are difficult to discover statistically, of relevance then is [22] which reports the number of events required for $80 \%$ power, for various sizes of the ratio, $r$, of the risk period to the observation period). Required events counts are in the decades for events that are statistically tractable (given moderate effects sizes), in fact all are less than 100 . Given such observations we proceeded pragmatically (without an explicit power calculation), by extracting from the RCGP RSC registry dataset all cases of vaccinations exposures in years 2010/11-2017/18, extracting between 300,000 and 500,000 per year.

This is an observational study and we acknowledge the limitations that this entails; we include a study design diagram to aid the reader in assessing potential sources of bias.

We have employed a study design that attempts to limit bias. For example, SCCS model estimates are sensitive to small values of $r$. In this study $r$ is approximately 0.12 (44/365) and, accordingly is not considered short in relation to the observation period. We assume that ascertainment of cases is independent of vaccination histories and argue that this is a reasonable assumption. Observa-
Table 5

Relative incidence of adverse events AEI by manufacturers 0-7 days after vaccination.

\begin{tabular}{llll}
\hline Manufacturer & Season/Year & RI & CI (95\%) \\
\hline AstraZeneca & $2013 / 14$ & 1.09 & $0.98-1.21$ \\
& $2014 / 15$ & 1.18 & $1.09-1.28$ \\
& $2015 / 16$ & 1.19 & $1.11-1.29$ \\
& $2016 / 17$ & 1.26 & $1.17-1.36$ \\
BGP & $2017 / 18$ & 1.10 & $1.02-1.19$ \\
& $2010 / 11$ & 1.88 & $1.75-2.04$ \\
& $2011 / 12$ & 1.70 & $1.58-1.84$ \\
& $2012 / 13$ & 1.96 & $1.80-2.12$ \\
& $2013 / 14$ & 2.12 & $1.96-2.29$ \\
& $2014 / 15$ & 1.81 & $1.70-1.93$ \\
& $2015 / 16$ & 2.24 & $2.11-2.37$ \\
& $2016 / 17$ & 2.31 & $2.17-2.47$ \\
& $2017 / 18$ & 2.29 & $2.16-2.43$ \\
Grucell & $2011 / 12$ & 2.14 & $1.88-2.45$ \\
& $2012 / 13$ & 2.03 & $0.68-6.08$ \\
& $2013 / 14$ & 1.44 & $0.78-2.66$ \\
& $2010 / 11$ & 0.76 & $0.37-1.56$ \\
& $2011 / 12$ & 1.07 & $0.56-2.02$ \\
& $2012 / 13$ & 1.36 & $1.12-1.66$ \\
& $2013 / 14$ & 2.01 & $1.72-2.36$ \\
& $2014 / 15$ & 1.09 & $0.79-1.49$ \\
& $2015 / 16$ & 1.88 & $1.50-2.35$ \\
& $2016 / 17$ & 3.85 & $3.50-4.23$ \\
& $2017 / 18$ & 2.18 & $1.90-2.50$ \\
& $2010 / 11$ & 1.63 & $1.48-1.79$ \\
& $2011 / 12$ & 1.97 & $1.80-2.16$ \\
& $2012 / 13$ & 1.81 & $1.71-1.92$ \\
& $2013 / 14$ & 1.91 & $1.83-2.00$ \\
& $2014 / 15$ & 1.95 & $1.88-2.03$ \\
& $2015 / 16$ & 2.10 & $2.03-2.17$ \\
& $2016 / 17$ & 2.23 & $2.16-2.31$ \\
& $2017 / 18$ & 2.14 & $2.07-2.21$ \\
& $2010 / 11$ & 1.56 & $1.44-1.69$ \\
& $2011 / 12$ & 1.36 & $1.26-1.46$ \\
& $2013 / 14$ & 1.63 & $1.55-1.72$ \\
& $2014 / 15$ & 1.69 & $1.62-1.77$ \\
& $2015 / 16$ & 1.69 & $1.62-1.76$ \\
& $2017 / 17$ & 1.90 & $1.82-1.97$ \\
& & 2.12 & $2.04-2.20$ \\
& 2.04 & $1.96-2.12$ \\
\hline
\end{tabular}


Table 6

Interaction terms for quadrivalent intramuscular (QIV) vaccination.

\begin{tabular}{|c|c|c|c|c|c|}
\hline \multirow[t]{2}{*}{ Year } & \multicolumn{2}{|c|}{$\begin{array}{l}\text { AEI 0-7 days } \\
\text { following } \\
\text { vaccination } \\
\end{array}$} & \multicolumn{3}{|l|}{ QIV vaccine } \\
\hline & RI & CI (95\%) & $\begin{array}{l}\text { Interaction } \\
\text { term }\end{array}$ & $\mathrm{CI}(95 \%)$ & $\begin{array}{l}\mathrm{p}- \\
\text { value }\end{array}$ \\
\hline $2015 / 16$ & 2.06 & $\begin{array}{l}2.00- \\
2.11\end{array}$ & 0.94 & $\begin{array}{l}0.76- \\
1.17\end{array}$ & 0.59 \\
\hline $2016 / 17$ & 2.20 & $\begin{array}{l}2.15- \\
2.25\end{array}$ & 1.86 & $\begin{array}{l}1.70- \\
2.03\end{array}$ & $<0.001$ \\
\hline $2017 / 18$ & 2.19 & $\begin{array}{l}2.13- \\
2.27\end{array}$ & 0.94 & $\begin{array}{l}0.90- \\
0.99\end{array}$ & 0.01 \\
\hline $\begin{array}{l}\text { All years (2015- } \\
\text { 2018) }\end{array}$ & 2.16 & $\begin{array}{l}2.13- \\
2.19\end{array}$ & 1.14 & $\begin{array}{l}1.10- \\
1.18\end{array}$ & $<0.01$ \\
\hline
\end{tabular}

Interaction terms for quadrivalent intramuscular (QIV) vaccination. An interaction term of $>1$ indicates an increase in the relative incidence of AEI compared to TIV in the 7 days after vaccination.

tion periods are defined on a rolling yearly basis, each includes an influenza season of interest. We have therefore avoided a 'before' and 'after' design, where the observation period is relative to the

\section{Table 7}

Relative incidence and interaction terms for patients receiving intranasal influenza vaccines.

\begin{tabular}{|c|c|c|c|c|c|c|}
\hline \multirow[t]{2}{*}{ Year } & \multicolumn{3}{|c|}{$\begin{array}{l}\text { AEI } 0-7 \text { days following } \\
\text { vaccination } \\
\end{array}$} & \multicolumn{3}{|c|}{ Intranasal vaccine } \\
\hline & RI & $\begin{array}{l}\mathrm{CI} \\
(95 \%)\end{array}$ & $\begin{array}{l}\mathrm{p}- \\
\text { value }\end{array}$ & $\begin{array}{l}\text { Interaction } \\
\text { term }\end{array}$ & $\begin{array}{l}\mathrm{CI} \\
(95 \%)\end{array}$ & $\begin{array}{l}\mathrm{p}- \\
\text { value }\end{array}$ \\
\hline $2013 / 14$ & 1.84 & $\begin{array}{l}1.80- \\
1.89\end{array}$ & $<0.001$ & 0.68 & $\begin{array}{l}0.61- \\
0.76\end{array}$ & $<0.001$ \\
\hline $2014 / 15$ & 1.80 & $\begin{array}{l}1.76- \\
1.85\end{array}$ & $<0.001$ & 0.78 & $\begin{array}{l}0.72- \\
0.85\end{array}$ & $<0.001$ \\
\hline $2015 / 16$ & 2.03 & $\begin{array}{l}1.99- \\
2.08\end{array}$ & $<0.001$ & 0.66 & $\begin{array}{l}0.61- \\
0.72\end{array}$ & $<0.001$ \\
\hline $2016 / 17$ & 2.25 & $\begin{array}{l}2.20- \\
2.30\end{array}$ & $<0.001$ & 0.63 & $\begin{array}{l}0.58- \\
0.68\end{array}$ & $<0.001$ \\
\hline $2017 / 18$ & 2.11 & $\begin{array}{l}2.06- \\
2.16\end{array}$ & $<0.001$ & 0.61 & $\begin{array}{l}0.56- \\
0.65\end{array}$ & $<0.001$ \\
\hline $\begin{array}{l}\text { All years, all ages } \\
\qquad(2013-2018)\end{array}$ & 2.03 & $\begin{array}{l}2.01- \\
2.05\end{array}$ & $<0.001$ & 0.65 & $\begin{array}{l}0.63- \\
0.68\end{array}$ & $<0.001$ \\
\hline $\begin{array}{l}\text { All years < } 5 \\
\quad(2013-2018)\end{array}$ & 1.76 & $\begin{array}{l}1.56- \\
1.99\end{array}$ & $<0.001$ & 0.60 & $\begin{array}{l}0.52- \\
0.68\end{array}$ & $<0.001$ \\
\hline
\end{tabular}

AEI: adverse event of interest.

Overall, relative incidence for patients of all ages and under 5 years receiving LAIV was $2.03(2.01-2.05)$ and $1.76(1.56-1.99)$ respectively. An interaction term of 0.60 (0.52-0.68) shows that the lower rate of AEI was not a function of the age of vaccine recipient.

\section{Table 8}

Relative incidence and interaction terms for patients receiving vaccine raised in mammalian cells.

\begin{tabular}{|c|c|c|c|c|c|}
\hline \multirow[t]{2}{*}{ Year } & \multicolumn{2}{|c|}{$\begin{array}{l}\text { AEI 0-7 days } \\
\text { following } \\
\text { vaccination }\end{array}$} & \multicolumn{3}{|c|}{ Mammalian cell vaccine } \\
\hline & RI & CI (95\%) & $\begin{array}{l}\text { Interaction } \\
\text { term }\end{array}$ & CI (95\%) & $\begin{array}{l}\mathrm{p}- \\
\text { value }\end{array}$ \\
\hline $2013 / 14$ & 1.84 & $\begin{array}{l}1.80- \\
1.89\end{array}$ & 1.07 & $\begin{array}{l}0.58- \\
1.96\end{array}$ & 0.83 \\
\hline $2014 / 15$ & 1.80 & $\begin{array}{l}1.76- \\
1.85\end{array}$ & 0.73 & $\begin{array}{l}0.53- \\
1.00\end{array}$ & 0.06 \\
\hline $2015 / 16$ & 2.03 & $\begin{array}{l}1.99- \\
2.08\end{array}$ & 0.87 & $\begin{array}{l}0.54- \\
1.43\end{array}$ & 0.59 \\
\hline $\begin{array}{l}\text { All years (2013- } \\
2015)\end{array}$ & 1.89 & $\begin{array}{l}1.87- \\
1.92\end{array}$ & 0.78 & $\begin{array}{l}0.61- \\
0.99\end{array}$ & 0.04 \\
\hline
\end{tabular}

AEI: adverse event of interest. vaccination day and loss of power may result from artificial shortening of observation period.

\section{Conclusions}

The incidence of AEIs is variable between vaccines and can be identified from routine data collected within a sentinel network. There are however limitations in the quality of routine data including brand-specific data about vaccine exposure and that some AEIs may not be reported to primary care. Notwithstanding we report that quadrivalent have more AEIs than trivalent vaccines, LAIV has a different pattern of respiratory and pyrexial AEIs, and cellular vaccines may have fewer. Sentinel networks could be developed to provide more robust brand specific comparisons. Knowledge of common AEIs associated with specific seasonal vaccination could be useful in reassuring patients.

\section{CRediT authorship contribution statement}

Joe W. Cross: Conceptualization, Methodology, Data, Formal analysis, Writing- original draft. Mark Joy: Conceptualization, Formal analysis, Writing - review and editing. Christopher McGee: Conceptualization, Data curation. Oluwafunmi Akinyemi: Writing - review and editing. Piers Gatenby: Conceptualization, Writing review and editing. Simon de Lusignan: Conceptualization, Methodology, Writing- review and editing.

\section{Declaration of Competing Interest}

The authors declare the following financial interests/personal relationships which may be considered as potential competing interests: SdeL received funding from GSK to conduct EMA specification enhanced surveillance of AEIs, through the University of Surrey. He has attended Sanofi, and Seqirus advisory boards.

\section{Acknowledgements}

Practices and patients of the Royal College of General Practitioners Research and Surveillance Centre (RCGP RSC), who allowed their pseudonymised clinical medical records to be used for this study. Nick Andrews (Public Health England) for his advice on analysis. Other team members; Rebecca Webb contributed to the study as RCGP RSC Primary care scientist ( $9^{\text {th }}$ April 2018 to $26^{\text {th }}$ October 2018).

\section{Funding source}

JWC received support from the Health Education England academic placement. Funders have no role in the collection, analysis and interpretation of data; writing of the report; and decision to submit article for publication.

\section{Appendix A. Supplementary material}

Supplementary data to this article can be found online at https://doi.org/10.1016/j.vaccine.2020.03.034.

\section{References}

[1] Ramsay LC, Buchan SA, Stirling RG, Cowling BJ, Feng S, Kwong JC, et al. The impact of repeated vaccination on influenza vaccine effectiveness: a systematic review and meta-analysis. BMC Med. 2019;17(1):9. https://doi. org/10.1186/s12916-018-1239-8.

[2] Pebody R, Warburton F, Ellis J, Andrews N, Potts A, Cottrell S, et al. End-ofseason influenza vaccine effectiveness in adults and children, UnitedKingdom, 2016/17. Euro Surveill 2017;22(44). https://doi.org/10.2807/1560-7917. 
[3] World Health Organisation. WHO recommendations on the composition of influenza virus vaccines, http://www.who.int/influenza/vaccines/virus/ recommendations/en/ (Accessed 18/03/2016).

[4] Ambrose CS, Levin MJ. The rationale for quadrivalent influenza vaccines. Hum Vaccin Immunother. 2012;8(1):81-8. https://doi.org/10.4161/hv.8.1.17623.

[5] Pebody RG, Sinnathamby MA, Warburton F, Andrews N, Boddington NL, Zhao $\mathrm{H}$, et al. Uptake and impact of vaccinating primary school-age children against influenza: experiences of a live attenuated influenza vaccine programme, England, 2015/16. Euro Surveill. 2018;23(25). https://doi.org/10.2807/15607917.ES.2018.23.25.1700496

[6] Centers for Disease Control and Prevention. How Influenza (Flu) Vaccines Are Made, https://www.cdc.gov/flu/protect/vaccine/how-fluvaccine-made.htm (Acessed 20/03/2016).

[7] Robertson JS, Cook P, Attwell AM, Williams SP. Replicative advantage in tissue culture of egg-adapted influenza virus over tissue-culture derived virus: implications for vaccine manufacture. Vaccine 1995;13(16):1583-8. PubMed PMID: 8578846.

[8] Barrett PN, Portsmouth D, Ehrlich HJ. Vero cell culture-derived pandemic influenza vaccines: preclinical and clinical development. Expert Rev Vaccines. 2013;12(4):395-413. https://doi.org/10.1586/erv.13.21.

[9] Chu C, Lugovtsev V, Golding H, Betenbaugh M, Shiloach J. Conversion of MDCK cell line to suspension culture by transfecting with human siat7e gene and its application for influenza virus production. PNAS 2009;106(35):14802-7. https://doi.org/10.1073/pnas.0905912106.

[10] Manini I, Trombetta CM, Lazzeri G, Pozzi T, Rossi S, Montomoli E. EggIndependent Influenza Vaccines and Vaccine Candidates. Vaccines 2017;5 (3):18. https://doi.org/10.3390/vaccines5030018.

[11] The Pharmaceutical Journal 2019 First cell-based quadrivalent vaccine available for 2019/2020 flu season. https://doi.org/10.1211/ PJ.2019.20206011. Acessed 2020 February.

[12] Armstrong PK, Dowse GK, Effler PV, Carcione D, Blyth CC, Richmond PC, et al. Epidemiological study of severe febrile reactions in young children in Western Australia caused by a 2010 trivalent inactivated influenza vaccine. BMJ Open. 2011;1(1):e000016. https://doi.org/10.1136/bmjopen-2010-000016.

[13] Haber P, DeStefano F, Angulo FJ, Iskander J, Shadomy SV, Weintraub E, et al. Guillain-Barré syndrome following influenza vaccination. JAMA 2004;292 (20):2478-81. PubMed PMID: 15562126.

[14] De Serres G, Boulianne N, Duval B, Rochette L, Grenier JL, Roussel R, et al. Oculo-respiratory syndrome following influenza vaccination: evidence for occurrence with more than one influenza vaccine. Vaccine. 2003;21(1920):2346-53. PubMed PMID:12744865.

[15] European Medicines Agency (EMA) Pharmacovigilance Risk Assessment Committee (PRAC). Interim guidance on enhanced safety surveillance for seasonal influenza vaccines in the EU. London: EMA 2014. http://www.ema. europa.eu/docs/en_GB/document_library/Scientific_guidance. Accessed 2016 July.

[16] Correa A, Hinton W, McGovern A, van Vlymen J, Yonova I, Jones S, et al. Royal College of General Practitioners Research and Surveillance Centre (RCGP RSC) sentinel network: a cohort profile. BMJ Open. 2016;6(4): https://doi.org/ 10.1136/bmiopen-2016-011092e011092.

[17] de Lusignan S, Dos Santos G, Byford R, Schuind A, Damaso S, Shende V, et al. Enhanced safety surveillance of seasonal quadrivalent influenza vaccines in english primary care: interim analysis. Adv Ther. 2018;35(8):1199-214. https://doi.org/10.1007/s12325-018-0747-4. Epub 2018 Jul 11.

[18] de Lusignan S, Dos Santos G, Correa A, Haguinet F, Yonova I, Lair F, et al. Postauthorisation passive enhanced safety surveillance of seasonal influenza vaccines: protocol of a pilot study in England. BMJ Open. 2017;7(5):. https:// doi.org/10.1136/bmiopen-2016-015469e015469.
[19] de Lusignan S, Ferreira F, Damaso S, Byford R, Pathirannehelage S, Yeakey A et al. Enhanced passive surveillance of influenza vaccination in England, 20162017-an observational study using an adverse events reporting card. Hum Vaccin Immunother. 2019;15(5):1048-59. https://doi.org/10.1080 21645515.2019.1565258. Epub 2019 Mar 20.

[20] de Lusignan S. Codes, classifications, terminologies and nomenclatures: definition, development and application in practice. Inform Prim Care. 2005;13(1):65-70. PubMed PMID: 15949178.

[21] Pathirannehelage S, Kumarapeli P, Byford R, Yonova I, Ferreira F, de Lusignan S Uptake of a Dashboard Designed to Give Realtime Feedback to a Sentine Network About Key Data Required for Influenza Vaccine Effectiveness Studies. Stud Health Technol Inform. 2018:247:161-5. PubMed PMID: 29677943.

[22] Petersen I, Douglas I, Whitaker H. Self controlled case series methods: an alternative to standard epidemiological study designs. BMJ 2016;12(354): i4515.

[23] Farrington P, Whitaker H, Weldeselassie YG. Self-controlled case series studies: a modelling guide with R. CRC Press; 2018.

[24] Whitaker HJ, Hocine MN, Farrington CP. The methodology of self-controlled case series studies. Stat Methods Med Res 2009;18(1):7-26.

[25] Team RC. R: A language and environment for statistical computing.

[26] Wickham H. tidyverse: Easily Install and Load the 'Tidyverse'. R package version 1.2. 1. R Core Team: Vienna, Austria; 2017.

[27] Grolemund G, Wickham H. Dates and times made easy with lubridate. J Stat Softw 2011;40(3):1-25.

[28] Tomas J, Developer A. Epitools: Epidemiology Tools. R package versión 0.5-0.

[29] Yoshida K, Bohn J. tableone: create 'table 1'to describe baseline characteristics. 2018. URL https://CRAN.R-project.org/package=tableone. $\mathrm{R}$ package version 0.9. $2018 ; 3: 7$.

[30] Wickham H. ggplot2: elegant graphics for data analysis. Springer; 2016 Jun 8.

[31] Arnold JB, ggthemes: Extra Themes, Scales and Geoms for 'ggplot2'. R package version 3.5.0. 2018.

[32] Remschmidt C, Wichmann O, Harder T. Frequency and impact of confounding by indication and healthy vaccinee bias in observational studies assessing influenza vaccine effectiveness: a systematic review. BMC Infect Dis 2015;17 (15):429. https://doi.org/10.1186/s12879-015-1154-y.

[33] Smith T, Noble M, Noble S, Wright G, McLennan D, Plunkett E. The English indices of deprivation 2015. London: Department for Communities and Local Government; 2015.

[34] Office for National Statistics. Adult smoking habits in the UK: 2017.

[35] Volling C, Coleman BL, Katz K, Simor AE, Muller M, Powis J, McElhaney J, McGeer A. Immunogenicity and reactogenicity of high- vs. standard-dose trivalent inactivated influenza vaccine in healthcare workers: a pilot randomized controlled trial. Clin Microbiol Infect 2019;25(2):217-24. https://doi.org/10.1016/i.cmi.2018.05.002.

[36] GiaQuinta S, Michaels MG, McCullers JA, Wang L, Fonnesbeck C, O'Shea A Green M, Halasa NB. Randomized, double-blind comparison of standard-dose vs. high-dose trivalent inactivated influenza vaccine in pediatric solid organ transplant patients. Pediatr Transplant 2015;19(2):219-28. https://doi.org $10.1111 /$ petr. 12419 .

[37] Dos Santos G, Nguyen BY, Damaso S, Godderis L, Martínez-Gómez X Eckermann T, et al. Brand-Specific Enhanced Safety Surveillance of GSK's Quadrivalent Seasonal Influenza Vaccine in Belgium, Germany and Spain for the 2018/2019 Season. Drug Saf 2020;43(3):265-79. https://doi.org/10.1007 s40264-019-00893-4.

[38] de Lusignan S, Hoghton M, Rafi I. Flu vaccination by pharmacists leads to suboptimal medical records. BMJ 2017;9(359):j5084. https://doi.org/10.1136 bmj.j5084. PubMed PMID: 29122753. 